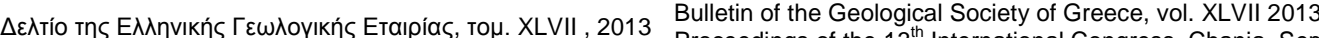
Proceedings of the $13^{\text {th }}$ International Congress, Chania, Sept.

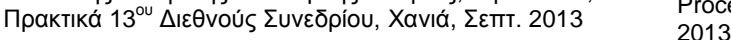

\title{
STABILITY ANALYSIS OF CONSTRUCTION AND DEMOLITION WASTE (CDW) DEPOSITS IN THE ABANDONED QUARRY OF PROFITIS ILIAS, KOZANI, GREECE
}

\author{
Konstantopoulou G. ${ }^{1}$ and Spanou N. ${ }^{1}$ \\ ${ }^{1}$ National Centre for Viable Development (NCVD), Institute of Geology and Mineral Exploration \\ (IGME), 1, Sp. Louis Str., Olympic Village, Acharnae, Greece, 13677, kongar@igme.gr, \\ spanou@igme.gr
}

\begin{abstract}
Abandoned quarries become favourable sites for uncontrolled waste dumps, causing major safety hazards because of potential mass movements. An old quarry, near the town of Kozani, is filled with $772.000 \mathrm{~m}^{3}$ Construction and Demolition Wastes $(C D W)$, containing a variety of materials (aggregates, wood, metals, plastics, bricks, soil etc.), in a wide range of fragment sizes, from clay to boulders. The size of particles and voids influence the behaviour of the filled slope, affecting both shear strength and drainage characteristics. Major factors that should be considered in a stability analysis for CDW, include waste material and soil cover composition, overall degree of compaction, moisture contented, permeability, pore pressure and shear strength parameters.

Shear strength parameters were chosen by bibliographic references based on specialized field tests of similar materials. The analyzed profiles computed slip zones of low thickness and range. Therefore, successive back analysis was conducted to the sites of mapped cracks, aimed to determinate the mechanical properties of the slope during the failure. Since, friction angle and bulk density were retained for back analysis, the cohesion was examined. Although deposits are composed of loose heterogeneous materials, which have not been condensed, cohesion exists owing to the "interlocking" of the varying particle size of materials.
\end{abstract}

Key words: uncontrolled waste dumps, mass movements, successive back analysis, "interlocking", protection measures.

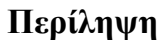

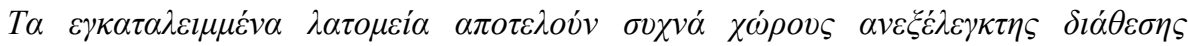

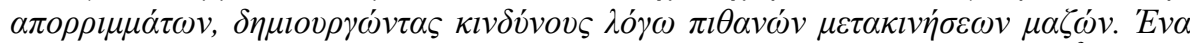

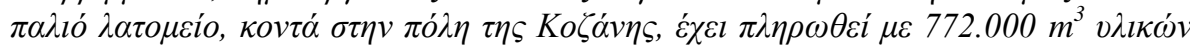

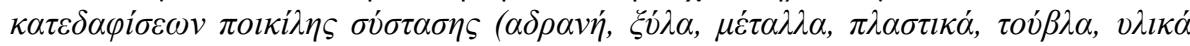

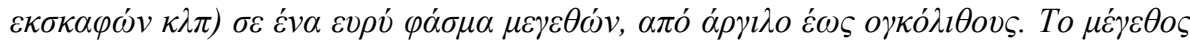

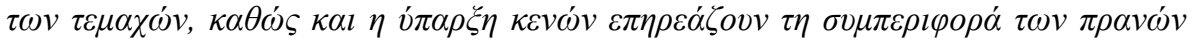

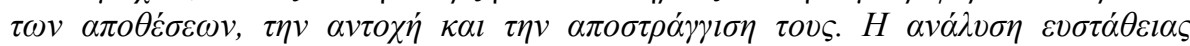

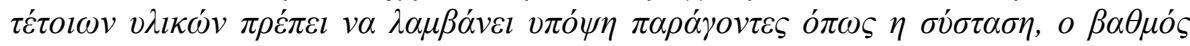

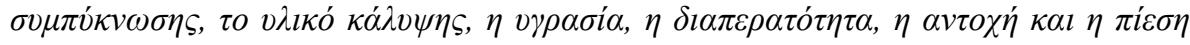
$\tau \omega v \pi o ́ \rho \omega v$.

XLVII, No $3-1706$ 


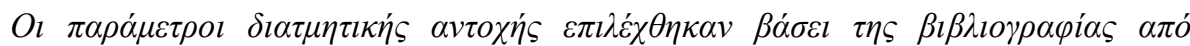

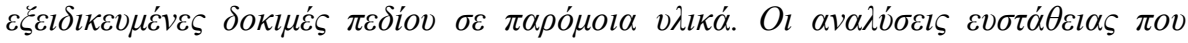

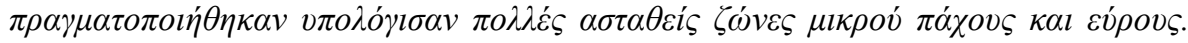

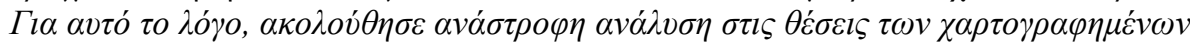

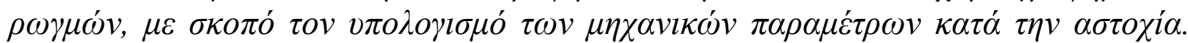

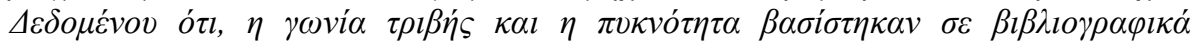

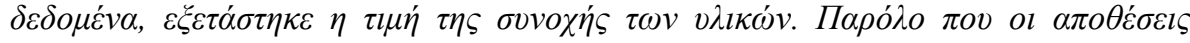

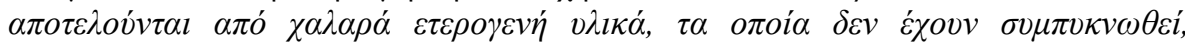

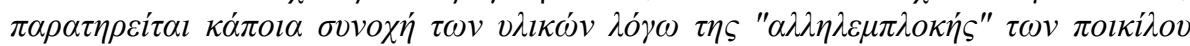

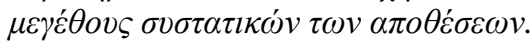

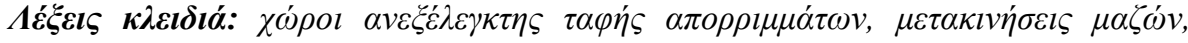


\section{Introduction}

Construction and Demolition Waste (CDW) describes material that is produced in the process of construction, renovation, or demolition of structures. Structures include buildings of all types (both residential and non-residential) as well as roads and bridges. Components of CDW debris typically include concrete, asphalt, wood, metals, gypsum wallboard and roofing. Land clearing debris, such as stumps, rocks and dirt, are also included in some definitions of CDW (Franklin Associates, 1999).

In the hilly area of Profitis Elias, situated northwest of Kozani town (Figure 1), four open pit limestone quarries had been in function during the decade 1971-1981 for the extraction of construction aggregates. After that, quarries were abandoned and the site remained unused creating environmental impact and safety issues.

The 6.5R magnitude earthquake's major macro seismic effect, manifested on the $13^{\text {th }}$ May 1995 in Kozani area, was the destruction of many buildings and infrastructures. In the following years, the reconstruction and large expansion of Kozani town due to the rapid urbanization and population growth resulted in the production of a great volume of C\&D waste. Municipal authorities tried to combine the rehabilitation of the abandoned quarries with the need of finding adequate disposal sites for CDW. Besides, it is a common practice in Greece to restore abandoned quarries by land filling.

The three lower and easiest accessed quarries have been partly filled and properly shaped to be used as a parking facility for the municipal vehicles and a local waste transfer station. The examined largest quarry was used exclusively for the deposition of the CDW materials, that has reduced environmental and safety risks and has provided significant cost and time savings for landfill disposal, due to its proximity to Kozani town. However, both the deposition method and the composition of CDW materials are not quite clear.

Recently, some failures have been occurred on the top debris/soil cover of the deposits, creating concern to the local authorities for a serious landslide. The aim of this study is the slope stability analysis of the CDW deposits and the investigation of failure mechanism, in order to propose the appropriate protection measures.

\section{Site Characteristics and Geometry of CDW}

The examined quarry is located in the south-eastern slope of Profitis Elias hill, between the altitudes of 805-875 m (Figure 2). Since the main body of CDW had been deposited soon after 1995 , it is assumed that the residual relief of the pit prior to deposition is roughly represented on the topographic map of HMGS (Hellenic Military Geographical Service), at 1:5.000 scale, version 1984 (Figure 3a), which is the only available for the quarry site. The pit had been developed along NE-SW direction with maximum length of $315 \mathrm{~m}$ and $100 \mathrm{~m}$ width. The quarry faces, steeply

$\underline{\text { XLVII, No } 3-1707}$ 
dipping to the East, had an average height of $45 \mathrm{~m}$. The above considerations approximately result to a total volume of about $1.500 .000 \mathrm{~m}^{3}$ of limestone that was exploited during the decade 19711981.

The CDW materials have been deposited in a stepped arrangement. Slope inclination among terraces is ranging between $33^{\circ}$ and $45^{\circ}$. The old pit has been completely filled, except some areas close to the western, northern and north-eastern boundary, where the residual rock quarry faces form slopes from 1 to $30 \mathrm{~m}$ high. The waste has been covered by a $50 \mathrm{~cm}$ thick top soil layer used for planting. Positive outcomes of this procedure have been the partial recovery of the natural relief and the reduction of the aesthetic distraction of the site, while slope stability conditions and potential pollution are questionable.

To calculate the thickness and hence the volume of CDW deposits, a detailed topographic map at 1:1.000 scale (Liakos, 2012), showing the current status of the quarry (Figure 3b), was contrasted to the one before the deposition (Figure 3a). The superimposition of the two digital elevation models reveals both the spatial distribution and the overall thickness of the deposits. Thus, the average thickness of CDW is estimated to $25 \mathrm{~m}$, reaching $42 \mathrm{~m}$ locally, while the total volume of the deposits is calculated to $772.000 \mathrm{~m}^{3}$ (Figure 3c). Apart from the above considerations, the thickness of the CDW deposits was estimated by a representative sampling borehole located around to the centre of the old quarry and found to be $25 \mathrm{~m}$.

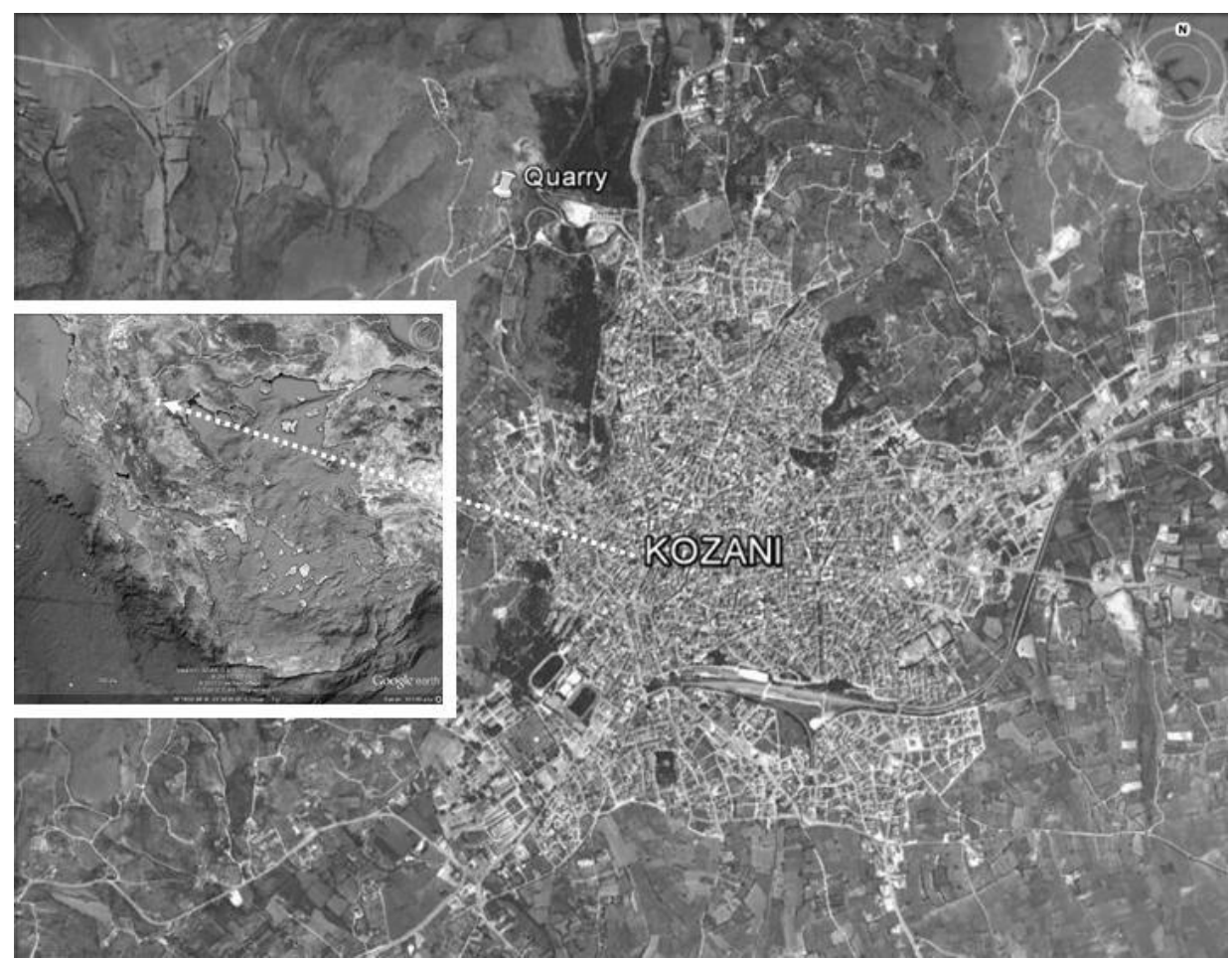

Figure 1 - The examined quarry is located in the vicinity of Kozani Town, in Profitis Elias area.

\section{Engineering Properties of CDW Deposits}

\subsection{Composition and Structure of CDW}

A detailed engineering geological map at 1:1.000 scale (Figure 4) was compiled for the study area using the topographic map provided by the Municipality of Kozani (Liakos, 2012). The 
composition of CDW materials can not be defined in detail, but can be estimated by the uncovered waste remnants as well as by the borehole survey. Typically, CDW appears to be a mixture of concrete, asphalt, wood, metals, plastics, rubber, textiles and soils (both waste products and soil cover). A wide range of particle sizes is encountered sorted from soil particles to large objects from the demolition procedure (reinforced concrete and masonry). The proportion of these materials varies within the site. These variations produce fundamental and significant differences in waste engineering behaviour. Supposed that the waste dumps are inert, they have been deposited directly on the native basement of the quarry without any geosynthetic liner system or drainage system installed before the waste deposition.

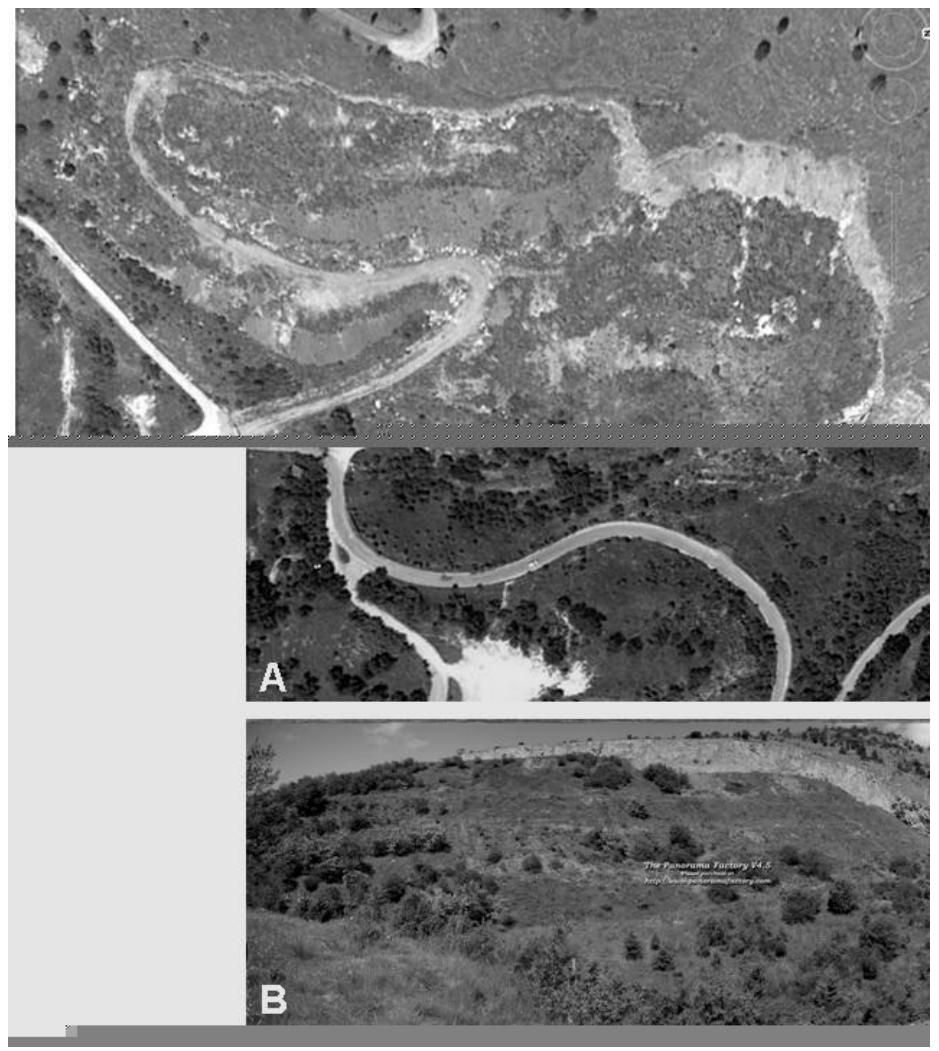

Figure 2 - Plan view (A) and panoramic photo (B) of the CDW deposits.

\subsection{Classification and Mechanical Properties of CDW}

The existing engineering classification systems for soils can not be directly applicable in the case of CDW materials. They may describe an individual but not well defined material class, since they exhibit an extreme diversity changing shape and proportion of their natural or synthetic components. Some classification systems have been proposed for Municipal Solid Wastes (MSW) (Siegel et al., 1990; Langer and Dixon, 2004) on the base of particular physical or mechanical parameters, but the current understanding of C\&D waste behaviour is far from being complete due to the lack of both agreed classification system and test standards, making it difficult to compare published results.

As a part of site data collection, one borehole was drilled on about the central of the CDW body to the depth of 29 m below ground surface, giving information about: i) waste material type and soil stratification, ii) permeability of CDW in specific depths, iii) strength and compressibility parameters, iv) depth to bedrock. Standard Penetration Tests (SPT) were performed to investigate the penetration resistance, compressibility and settlement of CDW. Although the materials of the

$\underline{\text { XLVII, No } 3-1709}$ 
studied quarry can not be classified as soils, SPT N values may be indicative of the relative density $\left(D_{\mathrm{r}} \%\right)$ variation with depth (Terzaghi and Peck, 1967). These indicative values corresponding from very loose to medium density materials due to the low compaction and existing voids within CDW body. Additionally, all in situ permeability tests considered very high permeable materials by calculating values for the coefficient $\mathrm{k}$ greater than $1 \times 10^{-2} \mathrm{~cm} / \mathrm{sec}$.
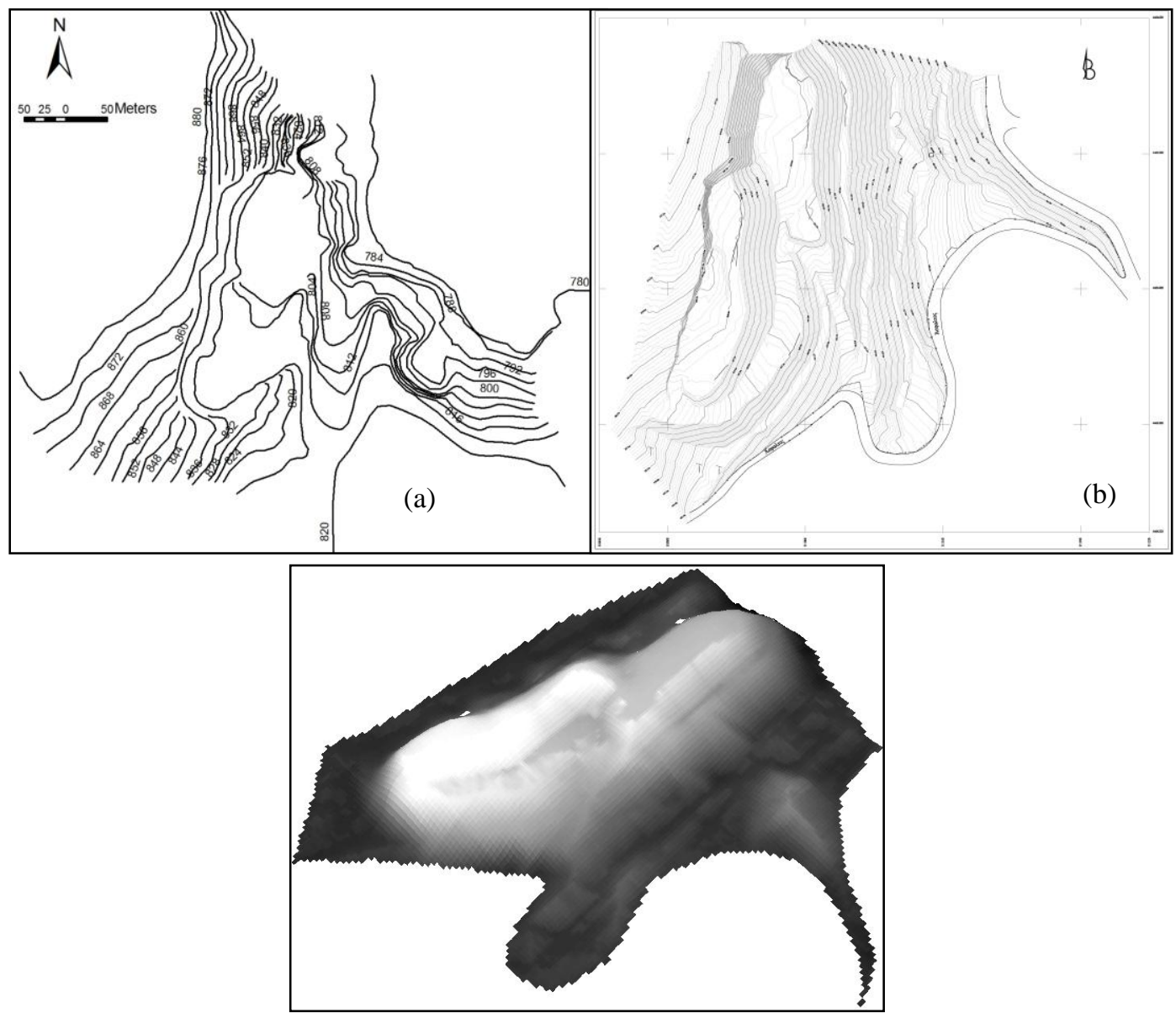

Figure 3 - (a) Topographic map (scale 1:5.000) of the abandoned quarry site (HMGS, 1984), (b) topographic map (scale 1:1.000) of the same area (Liakos, 2012) and (c) digital model interpreting the current thickness of the CDW deposits $(-10-42 \mathrm{~m})$, exported by the superimposition of the above base maps.

Regarding the engineering properties of CDW, there are no internationally accepted standard sampling and testing procedures for the waste materials at the moment. Thus, evaluating the engineering properties and hence the mechanical behaviour of CDW bodies is problematic, because it is difficult to quantify the contribution of the different waste components to the behaviour of the whole deposit. A review paper by Langer and Dixon (2004) concentrates on unit weight, compressibility, shear strength, lateral stiffness, in situ horizontal stress and hydraulic conductivity as the key parameters for the mechanical behaviour of the MSW materials.

Unit weight is mainly dependent on the waste composition, moisture content and the degree of compaction during deposition. Compressibility is related to the total settlement of the waste body. Apart from the mechanical compaction during waste deposition, secondary compression may also occur by self compaction from the weight of subsequent layers including soil cover. Due to the heterogeneous nature of waste constituents and their varied rates of decomposition, differential 
settlements may occur. Concerning the shear strength parameters, it is hard to obtain representative and reliable estimations for CDW due to the large particle size, heterogeneity, particular structure etc. The majority of the published studies for MSW give a large scatter of strength values taken mainly from direct shear box tests and back-analyses of failures (Jones et al., 1997; Stark et al., 2008).

\subsection{Characteristics of the Failures}

Ground failures are evident on the soil cover of the upper three terraces of the CDW body. The mode of failures includes profound, almost vertical extensional fractures, 10-60 m long and 5-40 $\mathrm{cm}$ wide with local expansions. They are wavy in form, usually running parallel and close to the edge of the terraces (Figure 4).

Slope failures on soil cover may be started by ravelling and collapse due to the movement of fines into larger voids or sudden collapse of hollow structures within the buried CDW deposits, which may cause significant settlement. When current tension cracks fill with water, the hydrostatic pressure exerted on their walls can lead to failure. At the same time, tension cracks may facilitate rainwater infiltration increasing seepage forces acting to cause slope movement.

\section{Stability Analysis}

In order to propose the appropriate prevention or protection measures, a stability analysis of the CDW deposits was performed using the computer package LARIX 5. The stability analysis is aiming both to the theoretical determination and interpretation of fractures appearance and development as well as the estimation of the critical mechanical parameters values of the deposited materials.

Stability analysis for CDW is considerably different from stability calculations in soil mechanics, due to the fact that they typically have an extreme variety of material types, sizes, and characteristics. Many factors should be considered in a proper stability assessment of the slope including waste type and composition, degree of compaction, cover material, density, moisture content, permeability, shear strength and pore pressure.

According to the above, shear strength parameters were chosen by bibliographic references based on specialized field testing in large samples of similar materials (Table 1). The used values were selected by evaluating the general description of CDW and estimating geotechnical properties for them using published correlations or assigning typical properties for similar materials (Stark et al., 2009). These values are: $\varphi=32^{\circ}, c=0 \mathrm{kN} / \mathrm{m}^{2}$ and $\gamma=15 \mathrm{kN} / \mathrm{m}^{3}$.

Table 1 - Representative physical and mechanical parameters of the CDW from the available bibliographic sources.

\begin{tabular}{|l|c|c|c|c|}
\hline \multicolumn{1}{|c|}{ Material } & $\begin{array}{c}\text { In-Place } \\
\text { Unit Weight } \\
\left(\mathbf{l b} / \mathbf{f t}^{\mathbf{3}}\right)\end{array}$ & $\begin{array}{c}\text { Saturated } \\
\text { Unit } \\
\text { Weight } \\
\left(\mathbf{l b} / \mathbf{f t}^{\mathbf{3}}\right)\end{array}$ & $\begin{array}{c}\text { Angle of } \\
\text { Internal } \\
\text { Friction } \\
(\mathbf{d e g r e e s})\end{array}$ & $\begin{array}{c}\text { Cohesion } \\
\left(\mathbf{l b} / \mathbf{f t}^{\mathbf{2}}\right)\end{array}$ \\
\hline $\begin{array}{l}\text { Mixed Construction Debris and } \\
\text { Soil }\end{array}$ & 96.0 & 116.0 & 32 & 0 \\
\hline
\end{tabular}

Four geotechnical sections, designed from a detailed topographic background, were used for the calculations and two series of analysis were conducted (Figure 4, A-A $\square, \mathrm{B}-\mathrm{B} \square \square, \mathrm{C}-\mathrm{C} \square$ and D$\mathrm{D} \square$ ). Janbu method was selected, since the slip surfaces constituted by linear segments and the failure mechanism is corresponded by a translational movement. 
Very low safety factors lower than 1 , and slip zones of low thickness and range were computed. For this reason successive back analysis was conducted to the places of mapped cracks, aimed to determinate the mechanical parameters of the slope during the failure. Since it has been assumed that the values of friction angle and bulk density taken by the bibliography feet to the current CDW materials, they were kept unchanged during the back analysis in order to estimate the cohesion (c) value. Despite the fact that the deposits are composed of heterogeneous materials, which have not been condensed, the overall cohesion of the slope is not zero, on account of the "interlocking" of varying size particles of the material. Geotechnical parameters outcome from the back analysis are: $\varphi=32^{\circ}, c=5 \mathrm{kN} / \mathrm{m}^{2}$ and $\gamma=15 \mathrm{kN} / \mathrm{m}^{3}$. Matching the instability phenomena observed on the slope, safety factor varies close to the limit equilibrium confirming the values of the shear strength parameters chosen for the analysis (Figure 6).

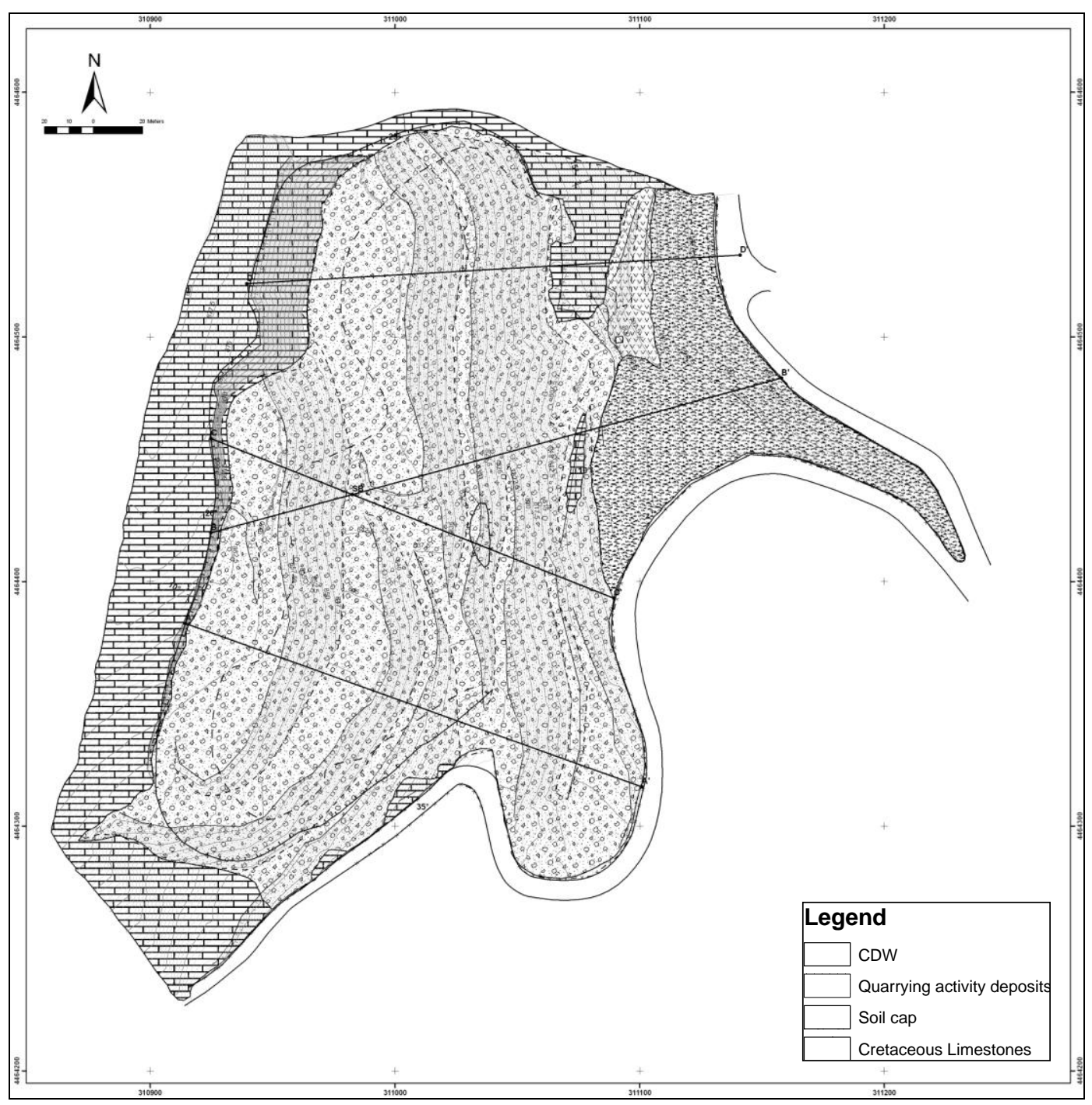

Figure 4 - Engineering geological map of the studied area.

\section{Discussion - Mechanism of Failure Development - Protection Measures}

The main reason for the occurrence of top soil tension cracks in the studied area is the settlement of underlying CDW deposits. Mechanisms resulting in settlement may be: a) Physical compression 
and creep (mechanical distortion, bending, crushing and re-orientation of particles), b) Raveling settlement (migration of small particles into voids between large particles), c) Collapse of containers and bridging components due to physical/chemical changes such as corrosion and oxidation. The magnitude of settlement may be controlled by the following factors: a) Initial composition of waste (grading, particle shape, material properties of components, e.g. metal, paper), b) Initial density and voids ratio, c) Layer type and thickness, d) Leachate levels and fluctuations, e) Environmental controlled factors (moisture content, temperature) (Manassero et al., 1996).

Apart the settlement mechanism, rain water plays an important role in the evolution of observed cracks. The high permeability of CDW materials reduce the surface flow of rainwater resulted in high rate water infiltration into the waste body. The leachate water increases pore water pressure within the fine grain layers of deposits, decreasing the shear strength of material.

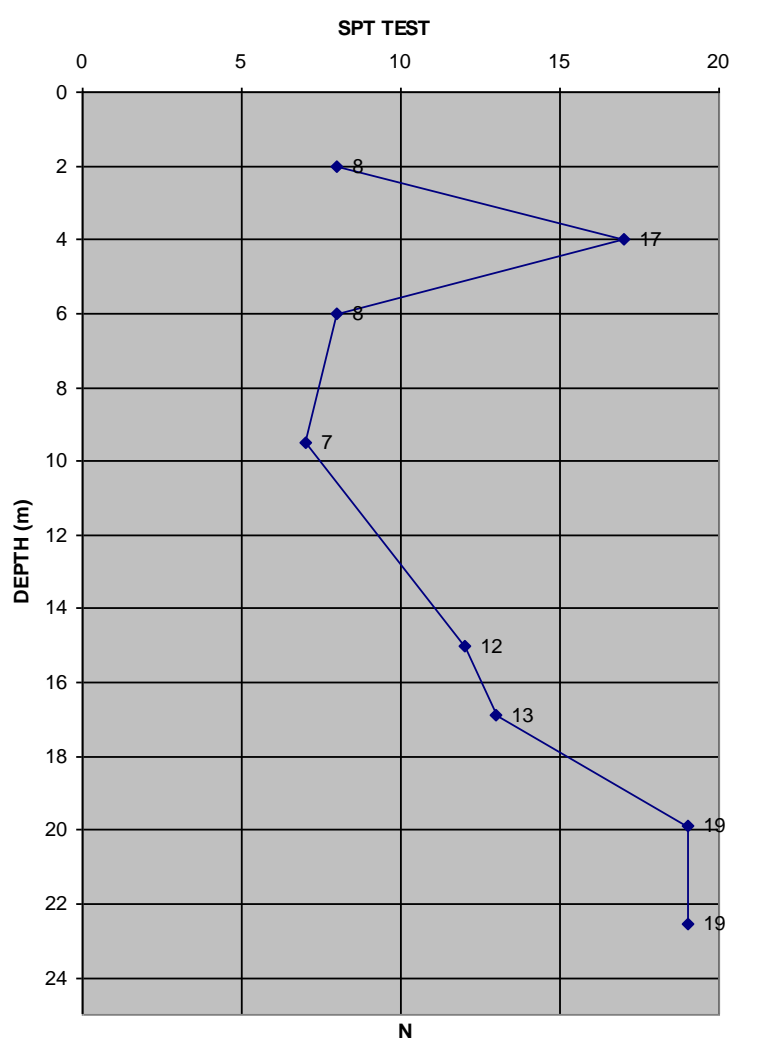

Figure 5 - Standard Penetration Test's results.

The protection measures aim on reduction of water infiltration, improving the leachate drainage and minimizing the settlements. Vegetation also could improve the stability conditions, as well as the filling of the open cracks.

The above examination of the dynamic evolution of cracks showed that the probability of failure of a large CDW volume is limited. However, to increase slope stability the following measures are proposed herein: 1) Closure of the existing cracks with clay material in order to reduce the water infiltration within the CDW body, 2) Improvement of the runoff system by configuration of the slope for the free removal of surface waters, 3) Vegetation thickening, 4) Installation of a flexible metal ring net barrier at the south-eastern boundary of the old quarry, following the superelevation of the residual rock quarry faces which operates as a natural barrier. 


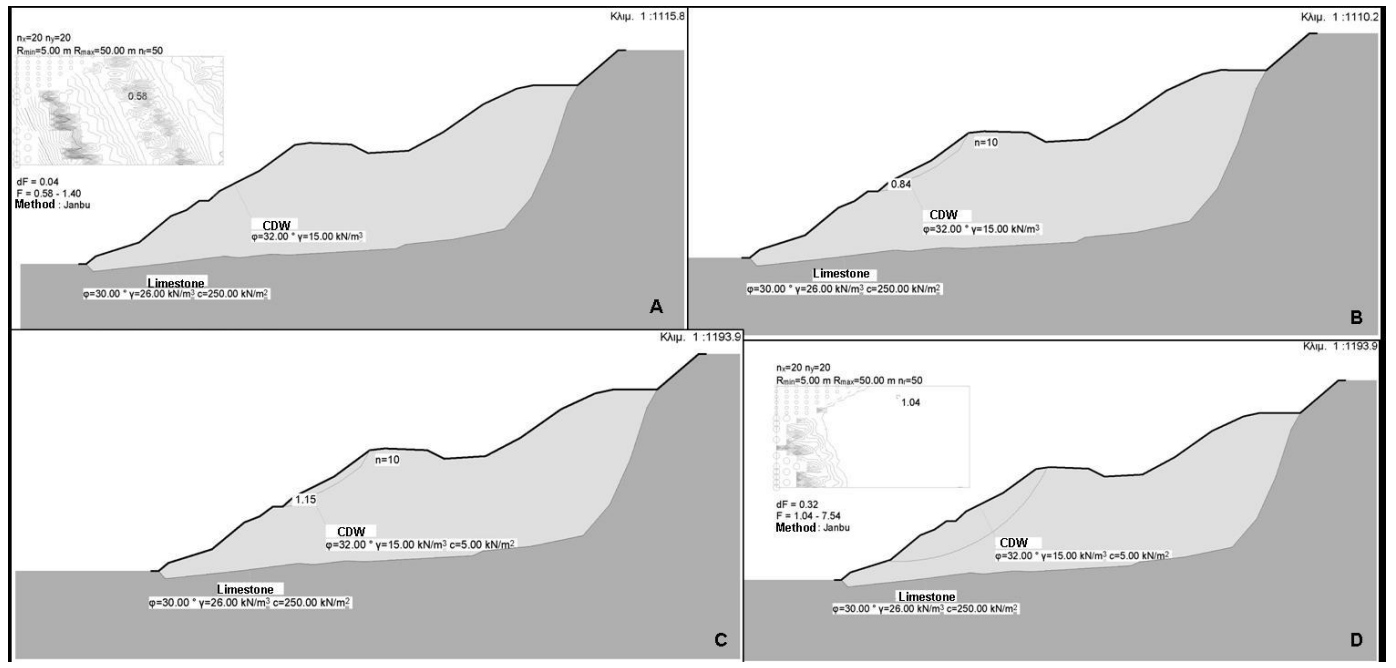

Figure 6 - Slope stability analysis performed in cross section BB $\square$ (A: Stability analysis without a predefined rupture surface, $B$ : Stability analysis considering existing tension cracks, C: Back analysis considering existing tension cracks, D: back analysis without a predefined rupture surface).

\section{Acknowledgments}

The current paper presents the results of the study titled: "Geological - Geotechnical Study at Prophet Elias area for the restoration of the old quarry", conducted by the Institute of Geology and Mineral Exploration of Greece (IGME) and assigned by Municipality of Kozani.

\section{References}

Franklin Associates, 1999. Characterization of Building-Related Construction and Demolition Debris in the United States, U.S. Environmental Protection Agency, Washington DC, June 1999.

Jones D.R.V. Taylor D.P. and Dixon N. 1997. Shear strength of waste and its use in landfill stability analysis. In: Yong R.N., Thomas H.R. (Eds), Proceedings Geoenvironmental Engineering Conference, Thomas Telford, pp. 343-350.

Langer U. and Dixon N. 2004. Mechanical properties of MSW: development of a classification system. In: Yong, R.N., Thomas, H.R. (Eds.), Proceedings Fourth British Geotechnical Association Geoenvironmental Engineering Conference, Integrate d Management of Groundwater and Contaminated Land, pp. 267-274.

Liakos C.V. 2012. Topographic map in 1:1.000 scale (in Greek).

Manassero M., Van Impe W.F. and Bouazza, A. 1996. Waste disposal and containment. Proc. 2nd Intl. congress on environmental geotechnics, Osaka, Japan, Rotterdam: Balkema 3: 14251474.

Siegel R.A., Robertson R.J. and Anderson D.G. 1990. Slope Stability Investigations at a Landfill in Southern California, Geotechnics of Waste Fill-Theory and Practice; ASTM STP 1070.

Stark T.D., Huvaj-Sarihan N. and Li G. 2009. Shear strength of municipal solid waste for stability analyses, Environ Geol (2009) 57: 1911-1923.

Terzaghi K. and Peck R. 1968. Soil mechanics in Engineering Practice, J. Wiley, INC. New York, 2nd edition, $729 \mathrm{pp}$. 